\title{
Predicting Forest Change in Phu Phan National Park, Thailand Using Multi-Temporal Landsat Satellite Images
}

\author{
Jaturong Som-ard ${ }^{\mathrm{a}, \mathrm{b}, *}$, Savittri Ratanopad Suwanlee ${ }^{\mathrm{a}, \mathrm{b}}$, Worawit Jitsukka ${ }^{\mathrm{a}, \mathrm{b}}$, Komin Cheunbanyen ${ }^{\mathrm{b}}$ \\ ${ }^{a}$ Department of Geography, Faculty of Humanities and Social Sciences, Mahasarakham University, Maha Sarakham Province, \\ 44150,Thailand, Jaturong Som-ard - jaturong.s@msu.ac.th, Savittri Ratanopad Suwanlee - savittri.s@msu.ac.th, Worawit Jitsukka \\ -worawit.j@msu.ac.th \\ ${ }^{b}$ Geography, Geoinformatics and Resources Management Research Unit, Faculty of Humanities and Social Sciences, \\ Mahasarakham University, Maha Sarakham Province, 44150, Thailand, Komin Cheunbanyen - kalasin.komin@ gmail.com \\ * Corresponding author
}

Keywords: Predicting forest change, land use change, OBIA, Phu Phan national park

\begin{abstract}
:
The Royal Forest Department of Thailand has permitted people to use the resources in national parks since 2005. It leads to a decrease in forest areas. This study aims to monitor and predict forest land change in Phu Phan National Park using Landsat 5 TM images in 1998 and 2008, and Sentinel-2 MSI image in 2018. The atmosphere correction was conducted for satellite images. Land use changes were classified by object base image analysis (OBIA), include forest, agriculture, built-up, water and miscellaneous. The land use maps were measured, and then the CA-Markov model was applied to predict the forest change in a year of 2028. The results demonstrate that overall accuracy (OA) of land use maps is $85.6 \%$, $88 \%$, and $89.6 \%$ in 1998, 2008 and 2018, respectively. The land use map in 2018 is more accurate than others because the high-resolution image and current data input. Moreover, the use of reference data nowadays has high potential and reality for classification. During 1998 to 2008, forest and built-up extended $45.35 \%$ and 5.07\%, respectively. Meanwhile, miscellaneous, agriculture, and water decreased by 41.38\%, 21.92\%, and 3.45\%. During 2008 to 2018, agriculture, miscellaneous, and built-up slightly increased by $21.92 \%, 14.75 \%$, and $12.26 \%$, respectively while forest and water decreased by $48.82 \%$ and $2.24 \%$, respectively. The predicted forest change in 2028 is a decrease by $10.49 \%$ due to land use change to miscellaneous, agriculture, built-up, and water area, as forest is likely to be trespassed for built-up and agriculture areas as a result of local population growth. The results of the study can be useful for planning and managing the national park in the future.
\end{abstract}

